A detailed description of these investigations will be published elsewhere.

Institute of Pharmacology,

University of Szeged. May 12.

1 Meier, R., and Bucher, K., Schweiz. Med. Wochschr., 146, 294.

\section{Influence of Hydrotropic Substances on the Sol/Gel Transformation of Blood Plasma in vitro}

JORPES ${ }^{1}$, studying the chemistry of heparin, and, before him, Demole ${ }^{2}$ and Fischer ${ }^{3}$, have insisted upon the importance of the - $\mathrm{SO}_{3} \mathrm{H}$ group for the inhibition of blood-clotting. Link et al. ${ }^{4}$ have proved that salycilates have an antiprothrombinxmic effect, which is about twenty times weaker than the equivalent dose of 'Dicumarol' (Quick $\left.{ }^{5}, \mathrm{McKennie}^{8}\right)$. In order to get comparable data between the retarding influence on blood-clotting and the chemical constitution, we have measured the effect of the following hydrotropic substances in vitro: the sodium salts of phenyl-sulphonic acid, 1,4-oxy-phenyl-sulphonic acid, salycilic acid, 1,3-phenyl-disulphonic acid, 1,3,5-phenyl-trisulphonic acid. The method consists in mixing in small test-tubes $0.1 \mathrm{ml}$. of normal oxalated blood-plasma (human) with $0.1 \mathrm{ml}$. of a mixture of phosphate buffer and hydrotropic substance, and $0.2 \mathrm{ml}$. 'Thromboplastin' (HoffmannLaRoche, Basle). The phosphate buffer consists of $M / 30$ potassium dihydrogen phosphate and disodium hydrogen phosphate, so as to give a $p H$ of $7 \cdot 2$. It contains, further, sufficient hydrotropic substance to make it one third molar.

Series of four test-tubes containing analogous mixtures are placed in a water-bath at $30^{\circ} \mathrm{C}$. After two minutes $0.2 \mathrm{ml}$. of $M / 40$ calcium chloride are added (time 0 ) and carefully mixed. Thus the volume of the final mixture is $0.6 \mathrm{ml}$. and the concentration of the retarding substance therein is $M / 18$. The four test-tubes are then mechanically waved (not shaken) in the thermostat at $30^{\circ} \mathrm{C}$., up to the time when the solution moves no longer as a liquid but becomes a firm gel. The moment when the sol/gel transformation is complete is sharply defined and takes place within 3-4 sec. for all the four test-tubes. In order to test the reproducibility, we have repeated the four-tube series three times. We found a variation of times within \pm 1.5 sec. so long as the sol/gel transformation takes place in less than $2 \mathrm{~min}$., and +2.5 sec. when the process takes longer. Besides the times for undiluted plasma we have also measured plasma-dilutions with saline of 60,50 and 40 per cent. If we plot the logarithmic values of these dilutions (c) against the logarithmic values of the times $(t)$ measured, the results give a straight line, the equation of which is

$$
t=k \times c^{-a} \text { (compare Legler }{ }^{7} \text { ). }
$$

The lowest line (I) is obtained without addition of a retarding substance. "If we compare the time gained with undiluted plasma with the times retarded by addition of $\mathrm{C}_{6} \mathrm{H}_{5} \mathrm{SO}_{3} \mathrm{Na}$ (II), $\mathrm{C}_{6} \mathrm{H}_{4}\left(\mathrm{SO}_{3} \mathrm{Na}\right)_{2}(\mathrm{~V})$ and $\mathrm{C}_{6} \mathrm{H}_{3}\left(\mathrm{SO}_{3} \mathrm{Na}\right)_{3}(\mathrm{VI})$, we find a proportion of $1: 1 \cdot 23: 4 \cdot 37: 7 \cdot 56$. The retarding effect of two $\mathrm{SO}_{3} \mathrm{Na}$-groups instead of one is, therefore, $3 \cdot 14$, and the effect of three such groups instead of two is $3 \cdot 19$. The three sulphonates which were tested have a different parameter $k$ but the same exponential factor $a$, as their lines have the same angle with the base

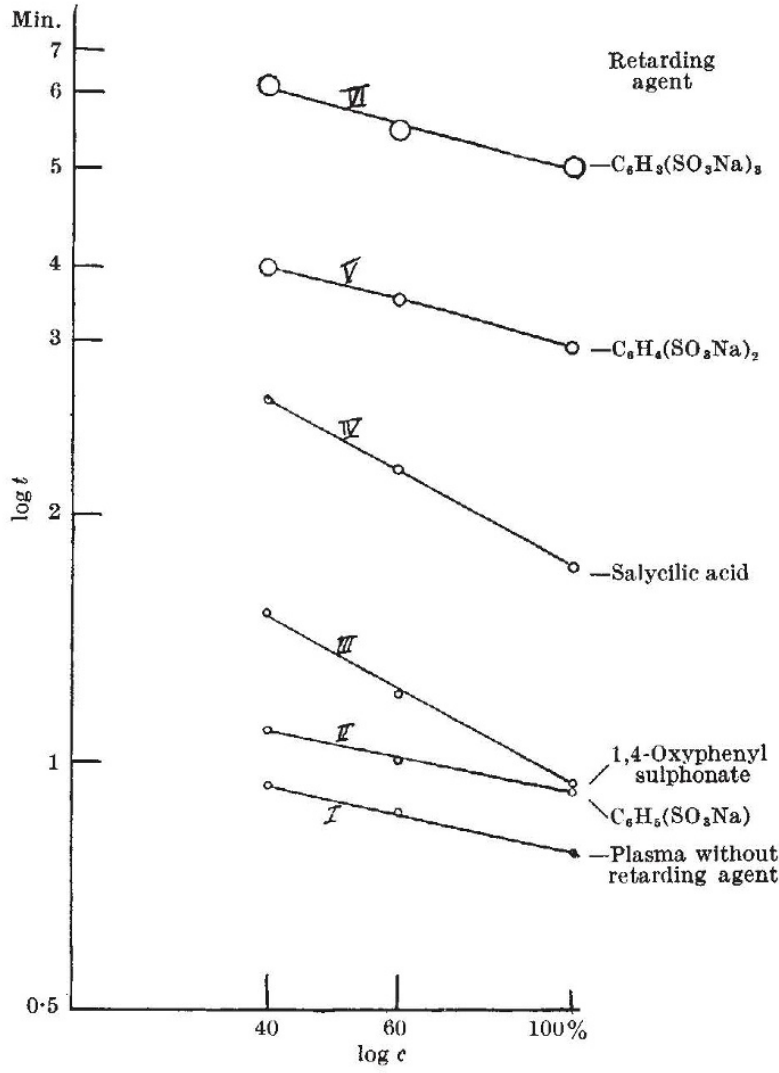

TIME OF PLASMA SOL/GEL TRANSFORMATION

The radius of the circles gives the precision with which the time of the plasma sol/gel transformation can be reproduccd. With tends to become less exact

line. It is noteworthy that both the lines of 1,4 . oxyphenyl-sulphonate (III) and of salycilic acid (IV) have a different $k$ and $a$ from the three sulphonated products. The retarding effect of the five hydrotropic substances which were evaluated increases in the same order as the substances as listed above. Our results are a new proof that the more $\mathrm{SO}_{3} \mathrm{Na}$. groups are present in the molecule of an aromatic substance the more efficient they become in retarding the clotting process of blood plasma in vitro. Their action, insignificant in vivo, is ascribed to the very small molecular weight, compared with those of heparin and the different synthetic polysulphuric acid esters. Therefore, their concentration in the blood-stream is diminishing too rapidly.

The measurement of the sol/gel transformation time with 1,4-oxyphenylsulphonate as a retarding agent is of such precision that we have founded upon it a routine procedure for the clinical laboratory. Details of results are in the press and will be published elsewhere.

University Medical Clinic,

Ch. Wunderly Zurich. May 18.

'Torpes, E., "Heparin" (London: Oxford Univ. Press, 1939); Z. physiol. Chem., 278, 7 (1043)

2 Demole, V., and Reinert, M., Arch. exp. Path. Pharmacol., 158, 211 (1930).

${ }^{8}$ Fischer, A., Biochem. Z., 240, 364 (1931).

${ }^{4}$ Iink, K. P., et al., J. Biol. Chem., 147, 472 (1943). Link, K. P., Federation Proc., i, 176 (1945).

${ }^{5}$ Quick, A. J., Amer. J. Physiol., 140, 212 (1943).

- McKennie, J., J. Amer. Med. A8soc., 128, 806 (1944).

"Legler, R., Helv. Chim. Acta, 28, 1512, 1673 (1943). 